\title{
Acute coronary syndrome in young Sub-Saharan Africans: A prospective study of 21 cases
}

Moustapha Sarr ${ }^{1}$, Djibril Mari Ba', Mouhamadou Bamba Ndiaye ${ }^{1 *}$, Malick Bodian¹, Modou Jobe ${ }^{1}$, Adama Kane ${ }^{1}$, Maboury Diao', Alassane Mbaye ${ }^{2}$, Mouhamadoul Mounir Dia', Soulemane Pessinaba' ${ }^{1}$, Abdoul Kane ${ }^{2}$ and Serigne Abdou $\mathrm{Ba}^{1}$

\begin{abstract}
Background: Coronary heart disease remains the leading cause of death in developed countries. In Africa, the disease continues to rise with varying rates of progression in different countries. At present, there is little available work on its juvenile forms. The objective of this work was to study the epidemiological, clinical and evolutionary aspects of acute coronary syndrome in young Sub-Saharan Africans.

Methods: This was a prospective multicenter study done at the different departments of cardiology in Dakar. We included all patients of age 40 years and below, and who were admitted for acute coronary syndrome between January $1^{\text {st }}, 2005$ and July $31^{\text {st }}, 2007$. We collected and analyzed the epidemiological, clinical, paraclinical and evolutionary data of the patients.

Results: Hospital prevalence of acute coronary syndrome in young people was $0.45 \%$ (21/4627) which represented $6.8 \%$ of all cases of acute coronary syndrome admitted during the same period. There was a strong male predominance with a sex-ratio (M:F) of 6 . The mean age of patients was $34 \pm 1.9$ years (range of 24 and 40 years). The main risk factor was smoking, found in $52.4 \%$ of cases and the most common presenting symptom was chest pain found in $95.2 \%$ of patients. The average time delay before medical care was 14.5 hours. Diagnosis of ST- elevation myocardial infarction in $85.7 \%$ of patients and non-ST-elevation myocardial infarction in $14.3 \%$ was made by the combination electrocardiographic features and troponin assay. Echocardiography found a decreased left ventricular systolic function in $37.5 \%$ of the patients and intraventricular thrombus in $20 \%$ of them. Thrombolysis using streptokinase was done in $44.4 \%$ of the patients with ST- elevation myocardial infarction. Hospital mortality was $14.3 \%$.
\end{abstract}

Conclusion: Acute coronary syndrome is present in young Sub-Saharan Africans. The main risk factor found was smoking.

Keywords: Acute coronary syndrome, Young Sub-Saharan African, Dakar

\section{Background}

Coronary heart disease remains the leading cause of death in developed countries. It is usually seen from the fifth to the seventh decades of life, but some cases in young people have been reported [1,2]. In Africa, while the work of the first European doctors that arrived on the continent claimed the low occurrence or even absence of atherosclerosis and its clinical manifestations,

\footnotetext{
* Correspondence: bambandiaye75@yahoo.fr

'Service de Cardiologie, CHU Aristide Le Dantec University Hospital,

PO Box 6633, Dakar étoile, Avenue Pasteur, Dakar, Senegal

Full list of author information is available at the end of the article
}

different schools of cardiology have shown not only their emergence, but especially their increase although at different rates in different countries $[3,4]$. On the other hand, few studies have been published on young people (5).

The objective of this work was to study the epidemiological, as well as the clinical and evolutionary peculiarities of acute coronary syndrome (ACS) in the young Sub-Saharan Africans of age 40 years and below.

\section{Methods}

This was a prospective multicenter study conducted at the respective cardiology departments of Aristide Le Dantec

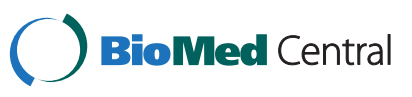


University Hospital, Grand Yoff General Hospital and Principal Hospital of Dakar over a period of 31 months (January $1^{\text {st }} 2005$ to July $31^{\text {st }} 2007$ ), in Dakar, Senegal.

All patients with an age of 40 years and below, admitted for acute coronary syndrome on the basis of anginal pain at rest, suggestive electrocardiographic changes and elevated troponin I levels, were included. Patients with more than 40 years of age, those with stable angina, and those with semi-recent or sequel of coronary syndrome were excluded from the study.

We studied data on age, gender, past history including history of diabetes, hypertension, smoking, alcoholism, sedentarism (less than 30 minutes or more of moderateintensity physical activity on most days of the week), obesity; family history of coronary heart disease at a young age (before 55 years in men and 65 years in women), use of estrogen-progestin contraceptives, stable angina and stress.

We sought the presence of chest pain, dyspnea and gastrointestinal symptoms.

We also noted the time delay before admission, the management given, and the vital parameters (blood pressure, heart rate, respiratory rate, temperature, body mass index).

All patients had a complete physical examination and a laboratory assessment. Troponin I assay was done using Architect STAT chemiluminescent microparticle immunoassay (Abbot). The other tests included blood glucose level on admission, total cholesterol and its fractions, and triglycerides. On the ECG, we looked for subepicardial or subendocardial lesion, subepicardial or subendocardial ischemia, abnormal Q waves, rhythm and conduction abnormalities. We have also looked for signs of venous stasis on the chest $\mathrm{x}$-ray and evaluated using Doppler echocardiography (which was performed during the first 24 hours of admission), the left ventricle wall motion, left ventricular ejection fraction using Simpson's biplanar method, and the presence of intracavitary thrombus. Treatment modalities were evaluated as well as evolution during hospitalization.

The study protocol was approved by the Ethics Committee of the Ministry of Health and Social Welfare, Senegal (Comité d'éthique du Ministère de la Santé et l'Action Sociale). A signed consent form was obtained from each of the study participants.

The studied parameters were entered into an electronic questionnaire using Epi Info version 6.0 of the World Health Organization. Data analysis was performed using SPSS 15.0 (Statistical Package for Social Sciences). Quantitative data were expressed as mean \pm standard deviation.

\section{Results}

Hospital prevalence of acute coronary syndrome in young patients was $0.45 \%$ (21/4627), meaning 6.8\%
(21/309) of patients admitted for acute coronary syndrome during the same period. Eighteen patients $(85.7 \%)$ were males and three patients (14.3\%) were females, giving a ratio of $6: 1$. The mean age of patients was $34 \pm 1.9$ years with a range of 24 and 40 years. In women, the mean age was 37 years and among men it was 34 years.

The risk factors in our patients (Table 1) were dominated by active smoking found in 11 patients (52.4\%). The average number of pack-years was $8.10 \pm 2.3$ and ranged from 1 to 17 pack-years.

Five patients $(23.8 \%)$ had no risk factors, seven patients (33.3\%) had one risk factor and the remaining patients $(42.9 \%)$ had more than one.

Chest pain was present in 20 patients (95.2\%). In 65\% of cases, it was typical anginal pain and inaugural in $70 \%$ of cases. The average time delay before medical care was given was 14.5 hours, with extremes of 03 and 48 hours.

On admission, blood pressure was greater than or equal to 140 and/or $90 \mathrm{mmHg}$ in three patients (14.3\%). Average body mass index was $23.5 \pm 1.5 \mathrm{~kg} / \mathrm{m}^{2}$. No patient was found to be obese.

Systemic examination was strictly normal in 18 patients (95.2\%). Three patients however showed signs of left ventricular failure (Killip II).

Mean troponin I level found was $29 \pm 40.9 \mathrm{ng} / \mathrm{ml}(0.01$ to $401.6 \mathrm{ng} / \mathrm{ml}$ ). Two patients had levels below 0.05 $\mathrm{ng} / \mathrm{ml}$. Average blood glucose level was $1.2 \pm 0.4 \mathrm{~g} / \mathrm{l}$ $(0.6$ to $3.83 \mathrm{~g} / \mathrm{l})$. It was found to be $1.24 \mathrm{~g} / \mathrm{l}$ in 4 patients (21\%). Mean total cholesterol was $1.4 \pm 0.2 \mathrm{~g} / \mathrm{l}$ (0.85 to $2.58 \mathrm{~g} / \mathrm{l})$. Hypercholesterolaemia was present in two patients, LDL cholesterol greater than $1.6 \mathrm{~g} / \mathrm{l}$ in one patient and HDL cholesterol less than $0.4 \mathrm{~g} / \mathrm{l}$ in seven patients (41.2\%). Two patients had a triglyceride level greater than $1.5 \mathrm{~g} / \mathrm{l}$.

Electrocardiogram revealed an acute coronary syndrome with persistent ST-elevation in 18 patients $(85.7 \%)$ and non ST-elevation acute coronary syndrome in three patients $(14.3 \%)$.

Topographically, the anterior and inferior territories were the most represented and found respectively in 14

Table 1 Risk factors found in the study population

\begin{tabular}{lcc}
\hline Risk factors & Number & $\%$ \\
\hline Tobacco smoking & 11 & 52.4 \\
Stress & 9 & 42.9 \\
Sedentarism & 3 & 14.3 \\
Hypertension & 3 & 14.3 \\
Hypercholesterolemia & 2 & 9.5 \\
Heredity & 2 & 9.5 \\
Diabetes & 1 & 4.8 \\
\hline
\end{tabular}


(66, 7\%) and 7 patients (33.3\%). An extension to the right ventricle was observed in one patient. We also noted two cases of ventricular tachycardia and complete atrioventricular block in one patient.

Chest radiography showed a cardiomegaly in four patients (21\%). Doppler echocardiography revealed impaired segmental kinetics in 12 patients (60\%). The mean ventricular ejection fraction was $52.2 \pm 8.5 \%$ (20-80\%). Systolic dysfunction was found in six patients and left ventricular thrombus in four.

Concerning treatment, thrombolysis using streptokinase was performed in eight patients, accounting for $44.4 \%$ of patients with ST-elevation.

Low molecular weight heparin was used in 19 patients (90.5\%), aspirin in 20 patients (95.2\%), clopidogrel in 7 patients (33.3\%) beta blockers in 17 patients (81\%), angiotensin converting enzyme inhibitors in 17 patients (81\%), statins in 14 patients $(66.7 \%)$ and analgesics in 13 patients (62\%).

The evolution during hospitalization after a mean hospital stay of $18.7 \pm 4.5$ days ( $1-37$ days) was favorable in 18 patients $(85.7 \%)$. Three deaths $(14.3 \%)$ were recorded, two of which were due to sudden death from ventricular fibrillation and one due to cardiogenic shock.

\section{Discussion}

In our study, the prevalence of acute coronary syndrome before age 40 was $0.45 \%$ with an incidence of $6.8 \%$ on all patients with coronary heart disease hospitalized during the same period.

Data on the incidence of acute coronary syndrome in young people are rare in Africa [5,6]. However, Wade found a prevalence of $0.03 \%$ and an incidence of $5.7 \%$ [7].

This incidence of $6.8 \%$ is bringing our numbers in the range of the European and American literature (4-10\%) [8-12] and could be an evidence of a real epidemiological transition.

The mean age of our patients was 34 years. Tricot [13], and Dolder [8] found, respectively, a mean age of 36 years and 35.4 years. However in India the youngest age reported for acute coronary syndrome was in a 14 year-old [14].

Our study confirms male predominance as has been emphasized in previous works $[2,7,9,10,14]$.

Smoking was found to be the main risk factor and is often found in the occurrence of coronary events in young patients [15]. Indeed, most works on the occurrence of coronary syndrome in young patients have a disease pattern dominated by monotonous smoking $[9,16,17]$.

This is reflected in our work where smoking is found in $52.4 \%$ of cases. This rate seems more important in European series, where it has been reported to be up to 93\% [13]. The use of hard drugs, as was the case with one of our patients, may be associated with the occurrence of a coronary event $[18,19]$.

The delay in our work (14.5 hours) is close to what is found in some Africans like in Tunisia [20].This period is shorter in the European series [21,22].

Clinically, acute coronary syndrome in young patients does not appear much different from that of the elderly. This has been emphasized by several authors [9,14,23,24]. The picture of acute coronary syndrome is dominated by pain in both the young as well as in the elderly.

Elevation of troponin levels form part of the definition of acute coronary syndrome [25]. This high rate of troponin assay in our work translates into a better integration of this biological parameter in the management of acute coronary syndrome. Concerning cardiomegaly found in 4 patients on chest X-ray at admission, no conclusion could be drawn as data on the existence cardiomyopathies or other heart disease could be established.

In our study we found using Doppler echocardiography an impaired left ventricular systolic function in $37.5 \%$ of cases versus $63.3 \%$ found by Renambot J et al. However, the mean age of patients in this series was 47.1 years \pm 4 [26]. Left intraventricular thrombus in the apical region was found in $20 \%$ of our patients. These results confirm data from the literature $[27,28]$. Segmental abnormality observed in only $60 \%$ of the cases might be primarily the effect of thrombolytic therapy. Also the degree of myocardial damage may not have been severe enough to lead segmental abnormality.

The impact of thrombolytic therapy on mortality with a time-dependent effect has been reported by several studies [29-31]. It is now clear that thrombolysis can significantly reduce mortality of patients with acute coronary syndrome. In our work, steptokinase being the only available thrombolytic in our hospitals, was used in $44.4 \%$ of patients admitted with an ST-elevation acute coronary syndrome. The reasons for the low use of thrombolytics in this study were due to many factors including low awareness level of the population about acute coronary syndrome, poor transport and communication network to reach referral centers, lack of available electrocardiography in health centers which are located close to patients, delayed referral from health centers of suspected cases and inability to meet the high cost of thrombolytic treatment. The favorable outcome in young adults, as seen in our work (85.7\%) seems higher than that observed in the elderly.

Heart failure is a common and serious complication of acute myocardial infarction. It was present in our work in $14.3 \%$ of patients. This was found in $18.2 \%$ and $9.2 \%$ respectively in the series of Al-Khadra and Kanitz $[14,24]$. A relationship between age and heart failure has been reported by Magid with a greater frequency of occurrence in the elderly compared to young subjects [32]. 
The ventricular arrhythmias are responsible for $30-40 \%$ of deaths occurring during the first 12 hours of a myocardial infarction. In our work, ventricular fibrillation was responsible for two deaths during the acute phase.

\section{Conclusion}

The occurrence of acute coronary syndrome is a reality in young Sub-Saharan Africans. The main risk factor is smoking. Complications are not rare and the mortality remains high.

\section{Competing interests}

The authors declare that they have no competing interests

\section{Authors' contributions}

$M S, D M B, M B N$ and $S A B$ designed the study protocol, participated in the data collection and contributed in analyzing the data and writing of the draft manuscript. MB, MJ, AdK and MD participated in data analysis and critically revising the manuscript for important intellectual content. AM, MMD, SP and AK participated in study design and in data analysis. All authors have read and approved the final version of the manuscript.

\section{Author details}

'Service de Cardiologie, CHU Aristide Le Dantec University Hospital, PO Box 6633, Dakar étoile, Avenue Pasteur, Dakar, Senegal. ${ }^{2}$ Service de Cardiologie, Hôpital Général de Grand Yoff, Dakar, Senegal.

Received: 30 November 2012 Accepted: 2 December 2013 Published: 14 December 2013

\section{References}

1. Benomar $M$, Berrada $M$ : Fréquence et aspects épidémiologiques de l'infarctus du myocarde de l'adulte jeune marocain. Coeur et Med Inter 1973, XII(3):409-415.

2. Bensaid J: L'infarctus du myocarde de 20 à 40 ans. La revue du praticien 1979, 53:4091-4094.

3. Shavadia J, Yonga $\mathrm{G}$, Otieno $\mathrm{H}$ : A prospective review of acute coronary syndromes in an urban hospital in sub-Saharan Africa. Cardiovasc J Afr 2012, 23:318-321.

4. Shaper A: Cardiovascular studies in the Samburu tribe of northern Kenya. Am Heart J 1962, 63:437.

5. Wyndham $\mathrm{CH}$, Seftel HC, Pilcher GJ, Baker SG: Prevalence of hypercholesterolemia in young Afrikaners with myocardial infarction. Ischemic heart disease risk factors. S Afr Med J 1978, 71(3):139-142.

6. Charles D, Barabe P, Talbi D: Infarctus du myocarde en Algérie. A propos de 30 observations. Cardiol Trop 1982, 8(29):13-19.

7. Wade B, Djimadoum N, Charles D: L'infarctus du myocarde chez le jeune Sénégalais. Etude étiologique et clinique de 14 cas. Cardiologie Tropicale 1996, 22:39-44.

8. Dolder MA, Olivier MF: Myocardial infarction in young men: study of risk factors in nine countries. Br Heart J 1975, 37:493-503.

9. Joussein-Remacle S, Delarche N, Bader H, Bader H, Lasserre R, Estrade G: Facteurs de risque de l'infarctus du myocarde du sujet jeune: registre prospectif sur un an. Ann Cardiol Angeiol 2006, 55:204-209.

10. Kannel WB, Abbott RD: Incidence and prognosis of unrecognized myocardial infarction. N Engl J Med 1984, 311:1144-1147.

11. Migliaresi P, Celentano P, Palmieri V, Pezzullo S, Martino S, Bonito M, Guillaro B, et al: Knowledge of cardiovascular risk factors and awareness of non-pharmacological approach for risk prevention in young: the cardiovascular risk prevention project "help your heart stay young". Nutr Metab Cardiovasc Dis 2007, 17:468-472.

12. Ruiz-Bailen M, Dehayos EA, Ramos-Cadra JA, Díaz-Castellanos MA, Issa-Khozouz Z, Reina-Toral A, López-Martínez A, et al: Influence of age on clinical course, management and mortality of acute myocardial infarction in the spanish population. Int J Cardiol 2002, 85:285-296.

13. Tricot R, Laffay N, Fillatre D: L'infarctus du sujet jeune. In Entretiens de Bichat, (Médecine). Paris: Expansions scient.fr.ed; 1974:93-98.
14. Al-khadra AH: Clinical profile of young patients with acute myocardial infarction in Saudi Arabia. Int J Cardiol 2003, 91:9-13.

15. Thomas D: Athérosclérose. In Cardiologie. Paris: Ellipses; 1994:135-151.

16. Bauters C: De la plaque d'athérome à la plaque instable. In ANGOR De la douleur thoracique à la plaque vulnérable. Edited by François D. Paris: EDITIONS scientifiques \& LC; 2003:41-52.

17. Collet JP, Ripoli L, Choussat R, Lison L, Montalescot G: La maladie athérothrombotique coronaire du sujet jeune: état des lieux. Sang. Thrombose Vaisseaux 2000, 12:218-225. N²4

18. Hollander JE, Hoffman RS, Gennis P, Fairweather P, Feldman JA, Fish SS, DiSano MJ, et al: Cocaine-associated chest pain: one-year follow-up. Acad Emerg Med 1995, 2:179-184

19. Kloner RA, Rezkalla SH: Cocaine and the heart. N Engl J Med 2003, 348:487-517.

20. Mahdhaoui A, Bouraoui H, Majdoub MA, Ben Abdelaziz A, Trimeche B, Zaaraoui J, Jeridi G, et al: Délais de prise en charge de I'IDM en phase aiguë : résultats d'une enquête dans la région de Sousse (Tunisie). Ann Cardiol Angeiol 2003, 52:15-19.

21. De Lopagno SM: Syndrome coronarien aigu: analyse des délais de la prise en charge. Thèse Med, Genève 2004: . No 10397.

22. Pistavos C, Panagiotakos DB, Antonoulas A, Zombolos S, Kogias Y, Mantas Y, Stravopodis $P$, et al: Epidemiology of acute coronary syndromes in a Mediterranean country; aims, design and baseline characteristics of the Greek study of acute coronary syndrome (GREECS). BMC Public Health 2005, 5:23.

23. Benacerraf A, Castilloy-Fennoy A, Goffinet D, Krantz D: L'infarctus du myocarde avant 36 ans: à propos de 20 cas. Arch Mal Coeur 1978, 77(7):756-764.

24. Kanitz MG, Giovannucci SJ, Jones JS, Mott M: Myocardial infarction in young adults: Risk factors and clinical features. Emerg Med J 1996, 14:139-145

25. Capolaghi B, Charbonnier B, Dumonet M, Hennache B, Henninot J, Laperche $T$, et al: Recommandations sur la prescription, le dosage et l'interprétation des troponines cardiaques. Ann Biol Clin 2005, 63:245-261.

26. Renambot J, Traore I, Chauvet J, et al: Relative rareté des indications opératoires dans la maladie coronaire chez les noirs africains: etude de 90 cas. Cardiol Trop 1991, 17:89-95.

27. Ba A: Les cardiopathies ischémiques: étude prospective à propos de 69 cas colligés à la clinique cardiologique du CHU de Dakar. Thèse Med Dakar 2002. No. 11.

28. Mboup MC: Les syndromes coronariens aigus: etude prospective à propos de 59 cas colligés en milieu hospitalier dakarois. Thèse Med Dakar 2006. No. 71

29. EMERAS (Estudio Multicentrico Estreptoquinasa Republicas de America del Sur) Collaborative Group: Randomized trial of the late thrombolysis in acute myocardial infarction. Lancet 1993, 342:767.

30. LATE (Late Assessment of Thrombolytic Efficacity) Study Group: Late Assessment of Thrombolytic Efficacity (LATE) Study with alteplase 6-24 hours after onset of acute myocardial infarction. Lancet 1993, 342:759-766.

31. Weaver WD: Time to thrombolytic treatment: factors affecting delay and their influences on outcome. J Am Coll Cardiol 1995, 25:3S-9S.

32. Magid DJ: Older emergency departement patients with acute myocardial infarction receive lower quality of care than younger patients. Ann Emerg Med 2005, 46:14-21.

doi:10.1186/1471-2261-13-118

Cite this article as: Sarr et al:: Acute coronary syndrome in young SubSaharan Africans: A prospective study of 21 cases. BMC Cardiovascular Disorders 2013 13:118. 